\title{
there will still be spring
}

Again, there's snow. The tree trunks glow with car tires. Again, the speed's cut down, the wounds drip over the moss. A normal steering wheel couldn't save me, the European experience is like poisonous, green crepe paper, the circles are peeling off,

setting like gelatin. Monkeys have tiny, bright movements. Energy flows through Maria's colors. Weasels are the ally, weasels are the enemy, the theme is the ally, the theme is the enemy. When I broke through the first valley,

I was grabbed by clarity like a pair of pliers. The howling and hand washing of all the highways spilled over me. But here I use the ceremonial staircase, the prescribed walk, howls are for those who, with furious relief,

leap aside. At first sight, it seems

that they're only resting here. In truth, they age only like the yellowed paper in books, to the very end rendered instruments by wisdom. 